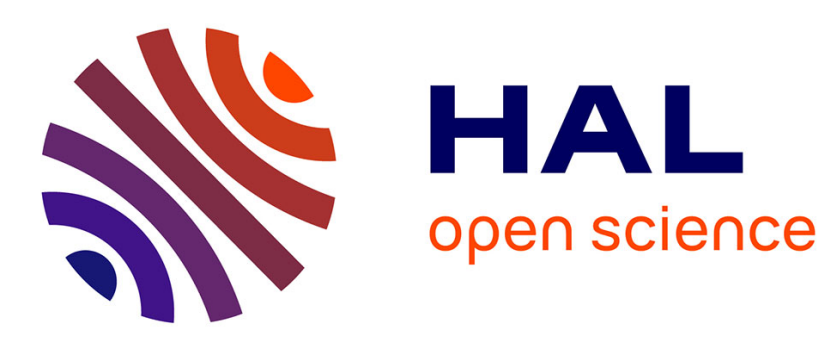

\title{
Springback of thick sheet AHSS subject to bending under tension
}

\author{
Hocine Chalal, Tudor Balan
}

\section{To cite this version:}

Hocine Chalal, Tudor Balan. Springback of thick sheet AHSS subject to bending under tension. International Journal of Mechanical Sciences, 2012, 59 (1), pp.104-114. 10.1016/j.ijmecsci.2012.03.011. hal-00800209

\section{HAL Id: hal-00800209 \\ https://hal.science/hal-00800209}

Submitted on 18 Mar 2013

HAL is a multi-disciplinary open access archive for the deposit and dissemination of scientific research documents, whether they are published or not. The documents may come from teaching and research institutions in France or abroad, or from public or private research centers.
L'archive ouverte pluridisciplinaire HAL, est destinée au dépôt et à la diffusion de documents scientifiques de niveau recherche, publiés ou non, émanant des établissements d'enseignement et de recherche français ou étrangers, des laboratoires publics ou privés. 


\section{Author's Accepted Manuscript}

Springback of thick sheet AHSS subject to bending under tension

Hocine Chalal, Sever-Gabriel Racz, Tudor Balan

PII:

S0020-7403(12)00067-7

DOI: doi:10.1016/j.ijmecsci.2012.03.011

Reference: MS2245

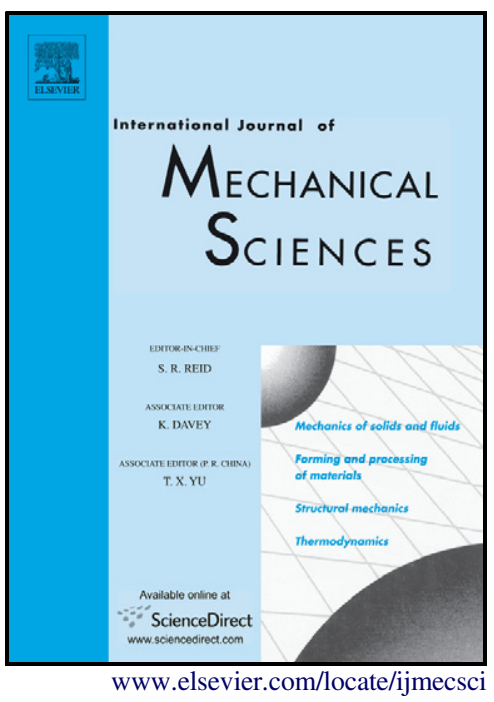

To appear in: International Journal of Mechanical Sciences

Received date: 7 June 2011

Revised date: 27 December 2011

Accepted date: 22 March 2012

Cite this article as: Hocine Chalal, Sever-Gabriel Racz and Tudor Balan, Springback of thick sheet AHSS subject to bending under tension, International Journal of Mechanical Sciences, doi:10.1016/j.ijmecsci.2012.03.011

This is a PDF file of an unedited manuscript that has been accepted for publication. As a service to our customers we are providing this early version of the manuscript. The manuscript will undergo copyediting, typesetting, and review of the resulting galley proof before it is published in its final citable form. Please note that during the production process errors may be discovered which could affect the content, and all legal disclaimers that apply to the journal pertain. 


\title{
Springback of thick sheet AHSS subject to bending under tension
}

\author{
Hocine Chalal $^{\mathrm{a}}$, Sever-Gabriel Racz ${ }^{\mathrm{b}^{*}}$, Tudor Balan ${ }^{\mathrm{a}}$
}

${ }^{a}$ Laboratoire d'Étude des Microstructures et de Mécanique des Matériaux, LEM3, UMR CNRS 7239, Arts et Métiers ParisTech - Metz, 4 rue Augustin Fresnel, 57078 Metz Cedex 03, France

b "Lucian Blaga” University of Sibiu, Faculty of Engineering, 4 str. Emil Cioran, 550025 Sibiu, Romania

\begin{abstract}
The springback behavior of four advanced high-strength sheet steels (Dual-Phase, TRIP, ferrite-bainite) with thicknesses ranging from 1.2 to $4 \mathrm{~mm}$ was investigated by means of the bending-under-tension (BUT) test. The applicability of several guidelines from the literature was investigated experimentally and numerically. The monotonic decrease of springback as back force increased was confirmed for this category of sheet steels, and a general trend for the non-linear influence of the tool radius was observed. The influence of numerical factors on the predicted values of springback was investigated, and conclusions and simple guidelines were drawn from the analysis with industrial sheet forming applications in mind.
\end{abstract}

Keywords: springback, bending-under-tension, AHSS, finite element simulation

\footnotetext{
* Corresponding author: Sever-Gabriel Racz (Gabriel.Racz@ulbsibiu.ro), tel: +(40) 269

216062 ext. 455; fax: +(40) 269217871.
} 


\section{Introduction}

Under pressure from environmental regulations and fuel consumption reduction policies, the automotive industry is moving towards wider use of weight-saving materials for the manufacture of car bodies-in-white. Along with aluminum and magnesium alloys, sheet advanced high strength steels (AHSS) are among the most promising such materials, combining increased in-use strength with good formability during forming stage. The industrial use of sheet AHSS faces several difficulties, including exacerbated springback compared to the classical, deep-drawing quality mild steels. Finite element analysis is regularly used during the die design stage to compensate die geometries with respect to the estimated part springback. It is also used for forming process optimization, e.g., to determine the optimal blank holding pressure in order to reduce springback while ensuring formability.

A variety of draw-bending experiments have been used to reveal the springback behavior of sheet metals. Most such tests use two-dimensional geometry for simplified analysis and simulation, while also being representative of many industrial parts. Flanged channels are typical for such analysis and they have served for various benchmark analyses [1]. The flow of sheet metal over the die radius induces side-wall curl after unloading due to non-uniform straining across the sheet thickness and the corresponding non-uniform stress distribution. Most studies in the literature emphasize the prominent influence of sheet tension on springback. However, the back force in a channel-drawing test is only indirectly imposed, as a result of the applied blank-holding force and the friction between the flange and both the die and blank-holder. Accordingly, specific springback tests have been designed so that the back force is directly controlled. One such test, the bending-under-tension (BUT) test, was initially designed for measuring friction forces and coefficients [2, 3]. In the BUT test, the sheet metal strip is drawn over a tool radius with its front and back sides forming a pre-defined angle, usually $90^{\circ}$. The front end of the specimen is drawn at constant velocity while a constant back force is applied at the back end, usually by means of hydraulic actuators as illustrated in Figure $1(\mathrm{a}$ and $\mathrm{b})$. Kuwabara and co-workers $[4,5]$ were the first to use this test to investigate springback; their analytical models captured the main trends although they were not able to precisely predict the springback geometries in all situations. Subsequently, Wagoner and coworkers [6-9] have thoroughly exploited this test for springback investigations. The guidelines set for an accurate finite element simulation of the BUT test and the clarification of the influence of secondary curvature, a characteristic of this particular test, are especially useful. Several dimensionless parameters were proposed to summarize the main effects. Specifically, the Searle parameter $\frac{w^{2}}{R t}$ characterizes the shape and influence of the secondary curvature, and the die radius vs. thickness ratio $\frac{R}{t}$ exhibits significant influence on the springback behavior. Low values of the die radius vs. thickness ratio have been shown to compromise the use of shell elements for springback simulations, and a drastic drop in springback measures is recorded. Several sheet metals were subjected to this test, including AHSS [10]. The influence of back force on springback was shown to be quasi-linear in most analyses, except for some sheet aluminum alloys [6] where a nonlinear trend was due to the inference of changes in secondary curvature. 

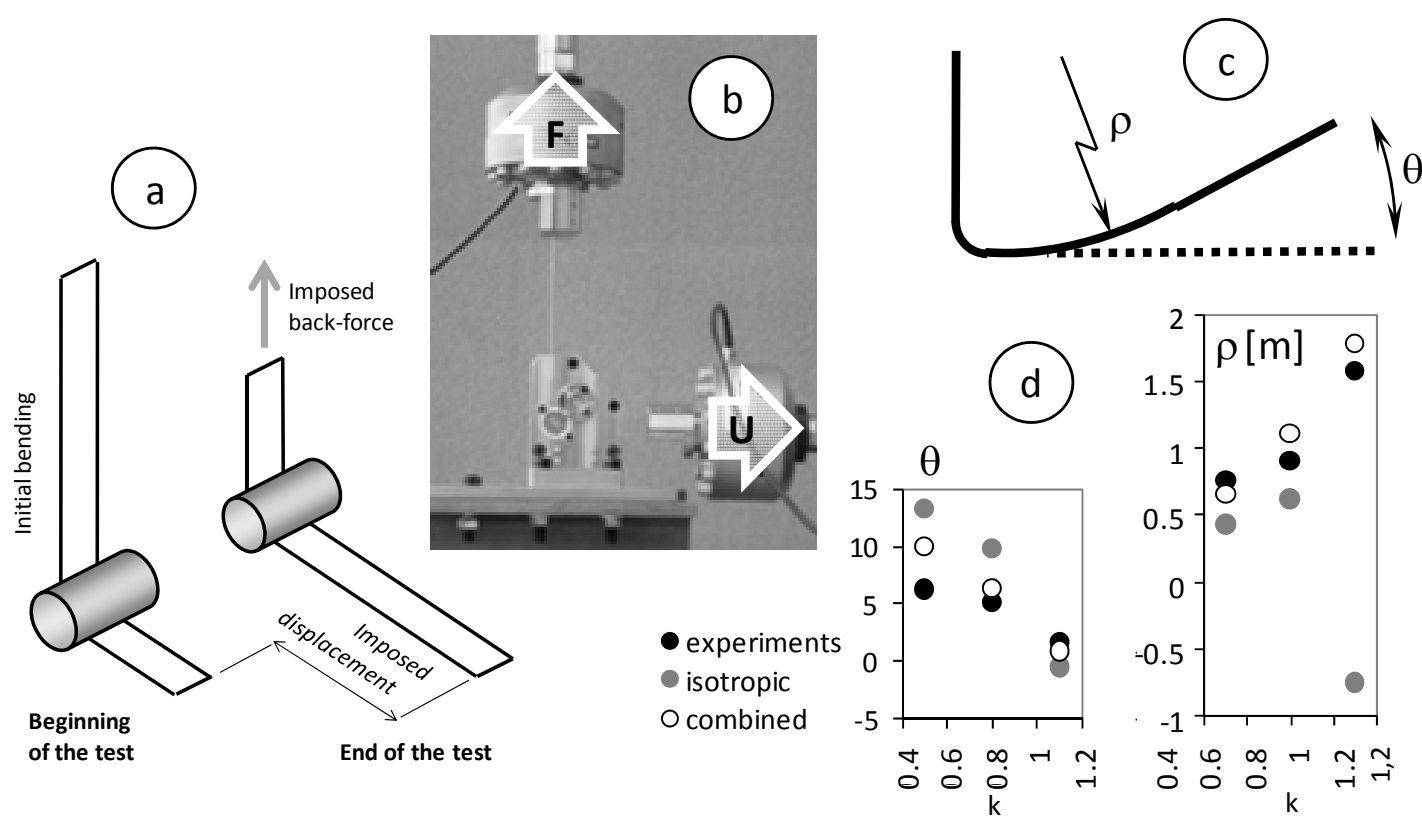

Figure 1 . The $90^{\circ}$ bending-under-tension test : a) schematic description; b) example of the LEM3 experimental set-up; c) springback measures; d) experimental and predicted springback for mild steel DC06 [11] using a tool radius of $6 \mathrm{~mm}$ and a 0.5 back force factor ${ }^{1}$.

Springback predictions were attempted both analytically [4] and by finite element simulations. The latter have been shown to be particularly sensitive to numerical factors and have been thoroughly investigated in [7,8]. Accurate springback predictions were shown (analytically) to require up to 50 through-thickness integration points (TTIP). However, many numerical experiments in the literature have indicated that this recommendation is often excessive. Two arguments seem to explain these apparently contradictory guidelines. The convergence of predicted springback measures when increasing the number of TTIP is not monotonic and it exhibits many oscillations. Thus a set of discrete values of TTIP may show an optimistic convergence rate. On the other hand, it has been shown [12] that the boundary conditions used for analytical springback computations have a considerable influence on the required number of TTIPs; force-type boundary conditions require a much smaller number of TTIPs for the same accuracy compared to the more classical displacement-type boundary conditions.

The aim of the current work was to investigate the springback behavior of four advanced high strength sheet steels. Materials with thicknesses of $2 \mathrm{~mm}$ and $4 \mathrm{~mm}$ were selected because the literature scarcely explores sheet metals with thicknesses larger than $1.5 \mathrm{~mm}$. The investigation was performed with industrial relevance in mind. For the numerical simulation the Abaqus finite element (FE) software was used with its built-in constitutive models and finite elements. Some of the guidelines from literature were reviewed in this framework to address their applicability in the case of the strength and thickness ranges considered in this study. More specifically, the influence of the back force, radius vs. thickness ratio, secondary curvature, hardening model, element type and mesh density were investigated.

\footnotetext{
${ }^{1}$ The back force factor is defined as the ratio between the applied back force, and the force required to plastify the actual sample in uniaxial tension.
} 
The materials and experimental procedure are presented in Section 2, together with experimental springback measurements. Section 3 discusses the general trends in terms of die radius vs. thickness ratio, back force factor and secondary curvature effects. In Section 4, the numerical simulation is described and its results are analyzed, before final conclusions are drawn in Section 5.

\section{Bending-under-tension experiments}

Dual phase, transformation-induced plasticity (TRIP) and ferrite-bainite sheet steels were used along with a drawing quality DC06 sheet steel, which served as reference. The materials were provided and characterized by third parties in the framework of a joint project. The tensile properties of the materials are listed in Table 1 [13]. Figure 2 shows the corresponding stress-strain curves obtained by tensile testing in the rolling direction. It is noteworthy that the four yield stresses of the AHSS are similar, with different values of ultimate tensile strength implying different hardening rates. The two TRIP steels with two different thicknesses had very similar behavior. The mean anisotropy coefficients of the AHSS sheets were close to unity (between 0.85 and 1.15) whereas the coefficient was 2.33 for the mild steel.

Table 1. Mechanical properties of the sheet steels used in the investigation [13].

\begin{tabular}{ccccc}
\hline Material & $\begin{array}{c}\text { Thickness } \\
{[\mathrm{mm}]}\end{array}$ & $\begin{array}{c}\text { Yield } \\
\text { stress } \\
{[\mathrm{MPa}]}\end{array}$ & $\begin{array}{c}\text { Ultimate } \\
\text { tensile } \\
\text { stress } \\
{[\mathrm{MPa}]}\end{array}$ & $\begin{array}{c}\text { Uniform } \\
\text { elongation } \\
{[\%]}\end{array}$ \\
\hline TRIP A & 1.26 & 506 & 859 & 22.1 \\
DP & 2 & 489 & 780 & 13.8 \\
TRIP B & 2 & 510 & 821 & 23.6 \\
FB & 4 & 494 & 586 & 13.3 \\
DC06 & 0.8 & 163 & 290 & 23.6 \\
\hline
\end{tabular}

Three of the tested sheets were thicker than those commonly reported in the literature, which are typically less than $1.5 \mathrm{~mm}$ thick. The width of the BUT samples was reduced to $12 \mathrm{~mm}$ for all of the tests in order to test 4-mm thick sheets and also to allow for back force factors up to 1.1. These particular geometries have seldom been used in the literature, and thus, they serve to extend the validation of experiment-based guidelines on springback. 


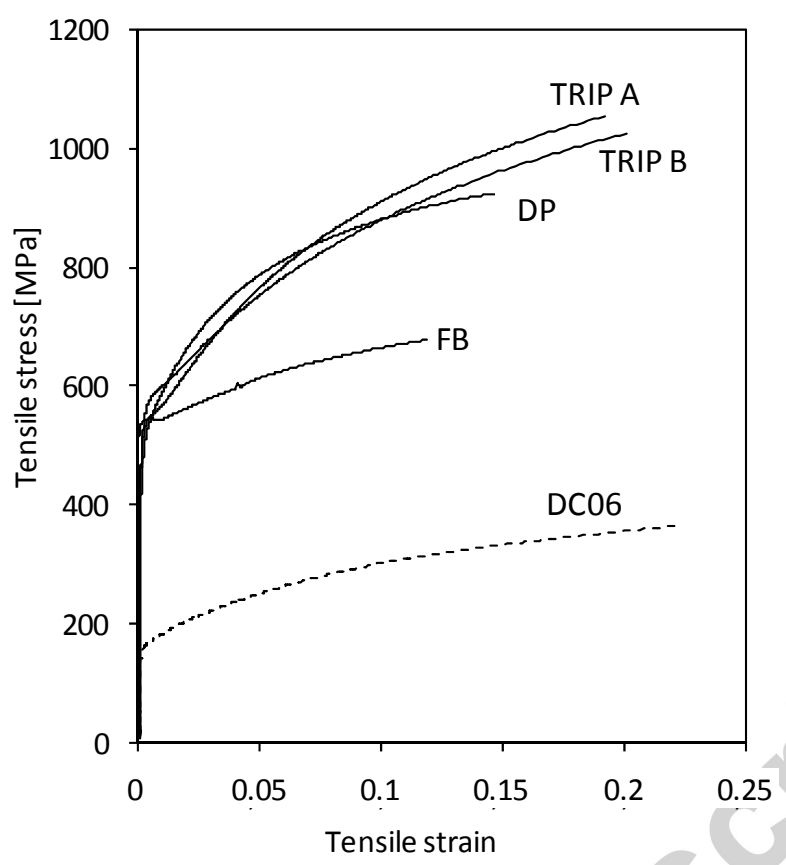

Figure 2. Tensile stress-strain curves of the four sheet AHSS (solid lines) and of the classical DC06 mild steel (dashed line) used as reference material [13].

Several measurements can be used to characterize springback. The springback angle $\theta$ (Figure 1c) is defined as the magnitude of the deviation from the shape of the part before unloading. In the BUT test, this angle is the result of elastic deformation in the tool radius zone where the sample only experiences bending, and the elastic deformation in the side-wall zone where the sample experiences bending and un-bending. The two angles corresponding to the two contributions can be measured separately, yet it was demonstrated that the errors associated with the two individual measurements are much larger than the error for $\theta$ [6]. In particular, the relative error for the bending zone is sufficiently large to prevent the extraction of any reasonable trend with regular measurement means $[6,11]$. Thus the total angle $\theta$ will be systematically used in this work. Another important parameter concerns the side-wall curl, because it is the main contribution to the overall shape change. At least three measurements were used to quantify the side-wall curl: the side-wall curvature [4], its radius $\rho$ [6], and the curl height over a pre-defined arc [10]. These three values are linked by straightforward geometrical relationships. Figure 3 depicts their variation as functions of the corresponding springback angle, over a range of angles typical for sheet metal springback. The wall radius $\rho$ exhibits very non-linear behavior, and an infinite discontinuity at zero prevents simple, intuitive interpretations of this springback measure. In contrast, the curl height and curl curvature exhibit remarkably linear trends within the range of angles relevant for springback in spite of the apparent nonlinearity of the equations. In the current investigation, the curvature will be used to characterize side-wall springback because it does not require an arbitrary choice of an arc-length for the measurement. 

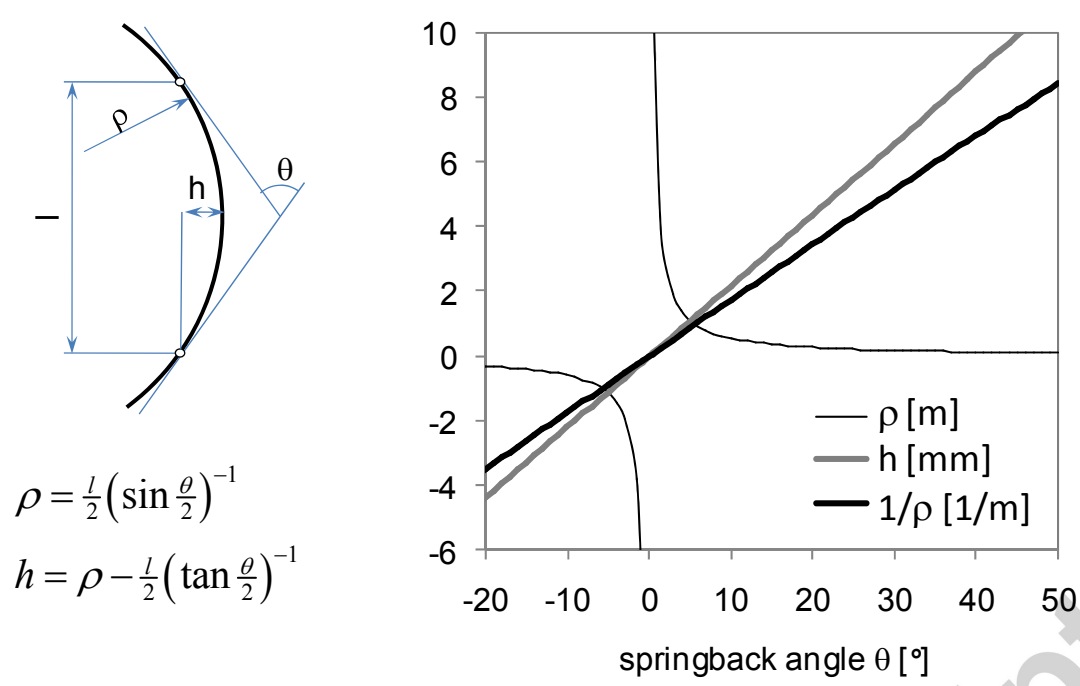

Figure 3. Comparison of side-wall curl / springback measures: curl radius $\rho$, curl curvature $\frac{1}{\rho}$, curl height $h$ and springback angle $\theta$.

The BUT tests were conducted using the test facility at the IUL Institute, Dortmund University [14]. Free roller tools were used with tool radii of 5, 10 and $15 \mathrm{~mm}$. Three levels of back force were set, determined for each material as pre-defined fractions of the force required to plastify the material. These so-called back force factors were equal to $0.5,0.8$ and 1.1. Most references in the literature report that springback diminishes quasi-linearly with back force. In some cases this diminution is strongly accelerated for back force factors larger than 0.8 , especially for aluminum alloys $[6,9]$. All of the test specimens were $400 \mathrm{~mm}$ long and $12 \mathrm{~mm}$ wide. The tests were conducted with the front actuator in constant velocity control, and the back actuator in load control. All materials and conditions were tested with duplicate samples, at a bending angle of $90^{\circ}$.

After the tests, the inside surface of all deformed, load-free samples was traced on paper and scanned at scale. Ten equi-distant points were digitized along the middle two-thirds of the side-wall subjected to bending-unbending. A Matlab code was written to fit these points to a circle and calculate its radius and curvature. In addition, the springback angle of the front, straight portion of the sample was measured with the same digitization technique with additional points. The measurement error associated with this procedure was less than $\pm 1^{\circ}$.

The experimentally measured springback results are summarized in Table 2 . The DC06 material was tested on a recently developed experimental setup [11] with a $6 \mathrm{~mm}$ tool radius. The two sheet materials with $2 \mathrm{~mm}$ thickness were the most thoroughly investigated. The remaining materials were tested over reduced ranges of tool radii (for small thicknesses) and back force (for the $4 \mathrm{~mm}$ sheet). Negative angle and curvature values designate the springforward phenomenon, which occurred for three configurations in the series. 
Table 2. Results of springback experiments.

\begin{tabular}{|c|c|c|c|c|c|}
\hline Material & $\begin{array}{c}\text { tool } \\
\text { radius } \\
{[\mathrm{mm}]}\end{array}$ & k & $\begin{array}{c}\theta \\
{\left[{ }^{\circ}\right]}\end{array}$ & $\begin{array}{c}\text { side-wall } \\
\text { curvature } \\
{\left[\mathrm{m}^{-1}\right]}\end{array}$ & $\begin{array}{r}\text { stroke } \\
{[\mathrm{mm}]}\end{array}$ \\
\hline \multirow{6}{*}{ TRIP A } & \multirow{3}{*}{5} & 0.5 & 57 & 6.51 & 150 \\
\hline & & 0.8 & 46 & 4.37 & 173 \\
\hline & & 1.1 & 19 & 1.76 & 165 \\
\hline & \multirow{3}{*}{10} & 0.5 & 56 & 6.17 & 170 \\
\hline & & 0.8 & 35 & 3.96 & 176 \\
\hline & & 1.1 & 18 & 1.89 & 160 \\
\hline \multirow{9}{*}{ DP } & \multirow{3}{*}{5} & 0.5 & 30 & 3.43 & 142 \\
\hline & & 0.8 & 13 & 1.62 & 147 \\
\hline & & 1.1 & -4 & -0.19 & 144 \\
\hline & \multirow{3}{*}{10} & 0.5 & 43 & 5.41 & 154 \\
\hline & & 0.8 & 33 & 3.70 & 169 \\
\hline & & 1.1 & 12 & 1.51 & 169 \\
\hline & \multirow{3}{*}{15} & 0.5 & 21 & 2.85 & 166 \\
\hline & & 0.8 & 18 & 2.51 & 166 \\
\hline & & 1.1 & 13 & 1.83 & 161 \\
\hline \multirow{9}{*}{ TRIP B } & & 0.5 & 22 & 3.37 & 147 \\
\hline & & 0.8 & 9 & 1.31 & 154 \\
\hline & & 1.1 & -5 & -0.26 & 139 \\
\hline & \multirow{3}{*}{10} & 0.5 & 25 & 3.12 & 161 \\
\hline & & 0.8 & 15 & 1.94 & 161 \\
\hline & & 1.1 & 9 & 1.17 & 164 \\
\hline & \multirow{3}{*}{15} & 0.5 & 32 & 4.19 & 156 \\
\hline & & 0.8 & 22 & 2.67 & 163 \\
\hline & & 1.1 & 11 & 1.28 & 165 \\
\hline \multirow{2}{*}{$\mathrm{FB}$} & 10 & \multirow{2}{*}{0.5} & -6 & -0.21 & 144 \\
\hline & 15 & & 4 & 0.72 & 140 \\
\hline \multirow{3}{*}{ DC06 } & \multirow{3}{*}{6} & 0.5 & 6 & 1.30 & 110 \\
\hline & & 0.8 & 5 & 1.10 & 110 \\
\hline & & 1.1 & 2 & 0.63 & 110 \\
\hline
\end{tabular}

\section{Analysis of experiments and discussion}

The experimental springback results for the five materials exhibited several common trends. Due to the large thicknesses, the tool radius vs. thickness ratio took smaller values than those regularly observed in the literature, especially for the tool radius of $5 \mathrm{~mm}$. Figure 4 (left) 
shows the impact of the $R / t$ ratio on the springback angle. These results confirm that increasing the $R / t$ ratio slightly reduces the springback in most cases. However, for $R / t$ smaller than a certain limit, the springback angle decreased when $R / t$ decreased, and this behavior even led to a sign change indicative of spring-forward. Although the tested materials had different thicknesses and mechanical behavior, except for the yield stress, it seemed that the critical value was in the range of 4-6 for all of the materials. This corroborates previous results [6], where mild steel, HSLA steel and aluminum alloys up to $1.5 \mathrm{~mm}$ thick were tested. The current analysis confirms the apparent generality of this behavior, which could be an effective means for springback control as long as formability is not affected. Indeed, critical $R / t$ ratios, below which fracture may occur, have been reported, which is especially important for AHSS [15]. Figure 4 also demonstrates that this trend is identical both in terms of springback angle and side-wall curvature.
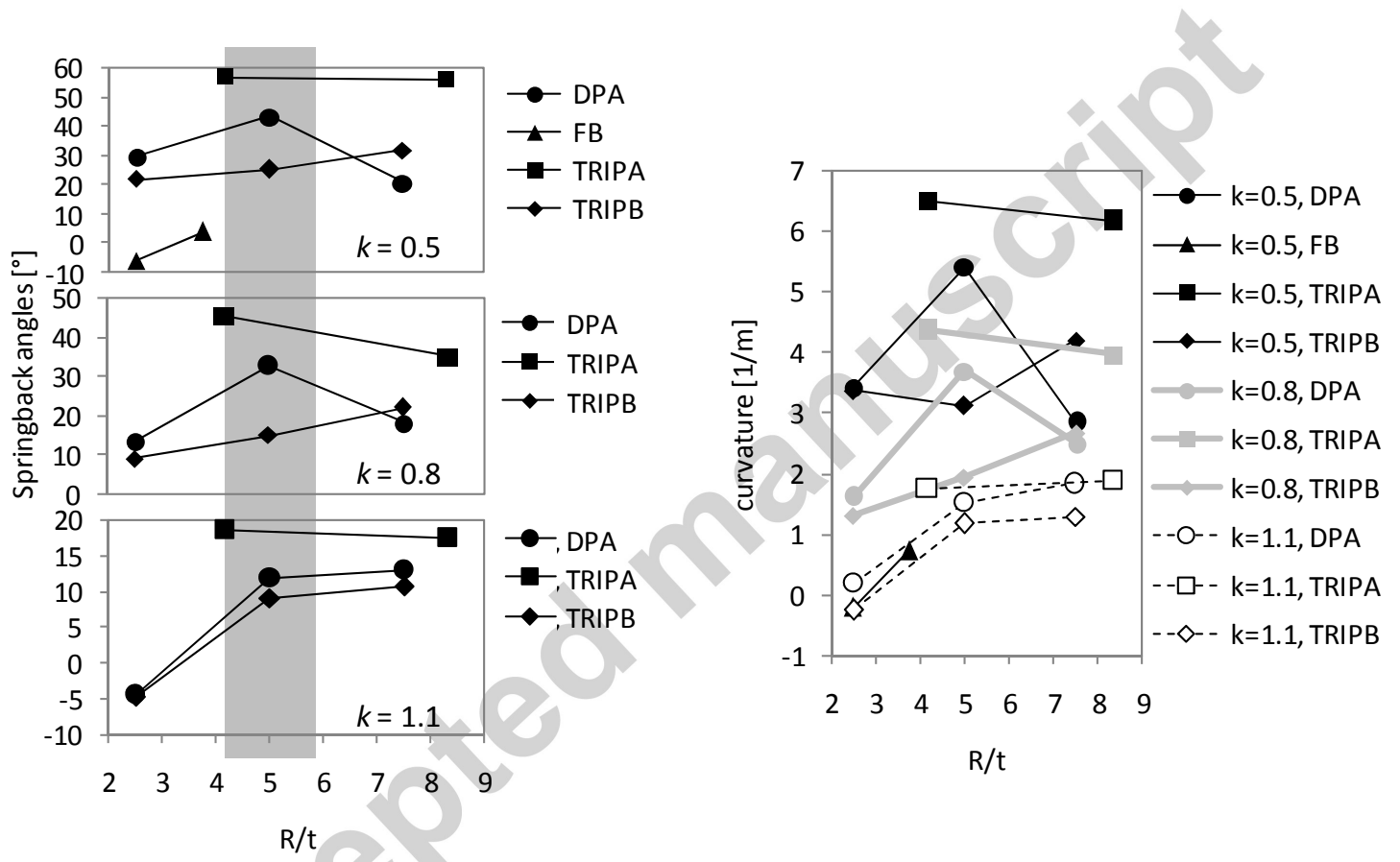

Figure 4. Influence of the die radius vs. sheet thickness ratio on the springback angle (left) and on the side-wall curvature (right).

The influence of the applied back force was quasi-linear in all cases (Figure 5). Larger $k$ values produced smaller springback, and the differences due to the different materials or tool radii also diminished as $k$ increased. Similarly, the range of springback angles diminished as $k$ increased; $k=0.5$ produced the largest experimental springback angle of $57^{\circ}$, which was three times larger than the $19^{\circ}$ maximum for $k=1.1$. 


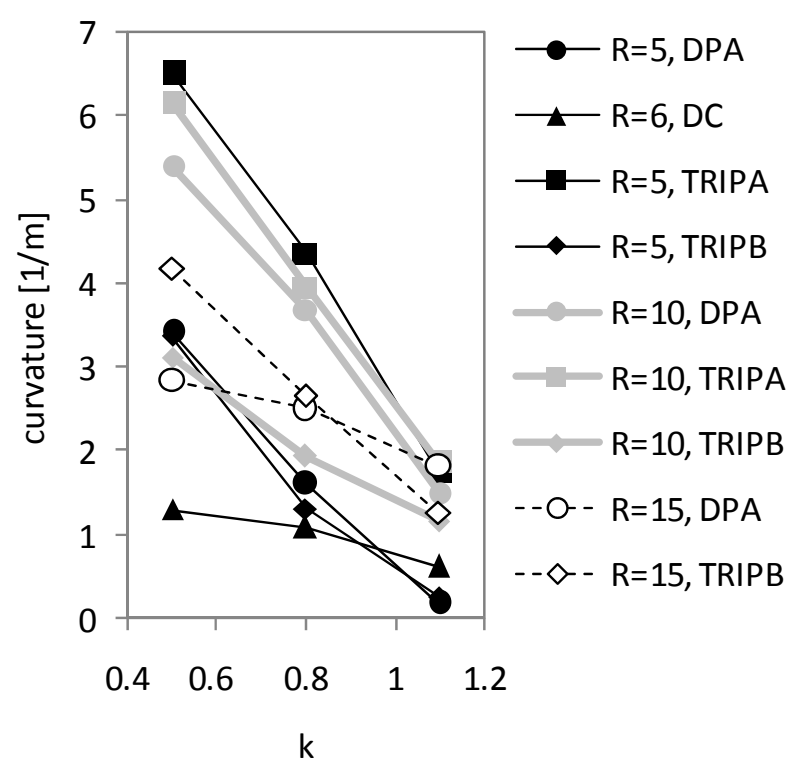

Figure 5. Influence of the back force factor $k$ on the side-wall curvature.

In the last decade, the secondary curvature of a sample has been also identified as an important factor that influences springback in a BUT test [9]. When subjected to bending and un-bending, the sample's cross-section deviates from the reference rectangle and it may take different shapes. The new shape depends on a dimensionless parameter defined by $\frac{w}{\rho} \cdot \frac{w}{t}$, were $w, t$ and $\rho$ are the sheet width, thickness and radius of the primary bending curvature, respectively [16]. For small values of this parameter (less than unity), the secondary curvature is constant. For values larger than 20, the secondary curvature approximates zero in the central area of the cross-section and increases in the vicinity of the edges. In several reports, it was found that important variations in Searle's parameter can interfere with the intended variation of another factor, i.e., back force or tool radius, and strongly modify the trends. Consequently, Searle's parameter was calculated for the current experiments. Given the relatively reduced width and large thickness, the results are less than unity in all cases, ranging from a maximum of 0.8 for the $1.2-\mathrm{mm}$ TRIP A (tool radius $5 \mathrm{~mm}$, back force factor 0.5 ) to 0.008 for the $4-\mathrm{mm}$ FB (tool radius $10 \mathrm{~mm}$, back force factor 0.5 ). Consequently, the secondary curvature of the cross-section was almost constant, and it could be determined by measuring its height $h$ at the middle of the cross-section (Figure 6, left). Under the assumption of uniform curvature, the bending stiffness of the cross-section could be calculated analytically with respect to the shifted center of gravity. Figure 6 (right) shows its variation with the secondary curl height. It is obvious from this figure that, for the given strip width and in the range of measured secondary curl heights (less than $0.24 \mathrm{~mm}$ in all cases), the stiffness variation is negligible for sheets that are $2 \mathrm{~mm}$ or thicker. Nonetheless, it can be important for thin sheets that are $1 \mathrm{~mm}$ or less. The variation of Young's modulus with plastic strain has more influence, as it is a factor for the moment of inertia in the bending stiffness formula (Figure 6, thick black curve). It is noteworthy that the centers of secondary and primary curvature were situated on the same side of the sample (synclastic surface). This shape was obtained during the forming process and does not change after springback. An anticlastic surface was observed during the bending stage, while the sample was in contact with the tool. The primary curvature suddenly decreased at the tool radius exit, causing the secondary curvature to change signs. The sample surface then becomes synclastic and remains so after 
the springback stage. This particular sequence of a cross-section shape change is wellreproduced by the FE simulations with 3D solid elements (see Section 4).

The thickness variation of the samples in the primary curl area was also measured, along with the secondary curvature. A thickness reduction was consistently observed in all of the configurations, with thickness variations as large as $0.4 \mathrm{~mm}$. For the $2-\mathrm{mm}$ sheets (DP A and TRIP B), the final thickness vs. initial thickness ratio varied from 0.94 when $k=0.5$ and $R=$ $15 \mathrm{~mm}$, to 0.82 when $k=1.1$ and $R=5 \mathrm{~mm}$. This factor had the strongest influence on the cross-section stiffness (Figure 6, thick gray curve) due to its weight in the expression for the moment of inertia. In the authors' opinion, thickness variation is one of the major factors preventing accurate springback predictions by both analytical methods as well as shell finite elements for cases in which the tool radius vs. thickness ratio becomes too small.
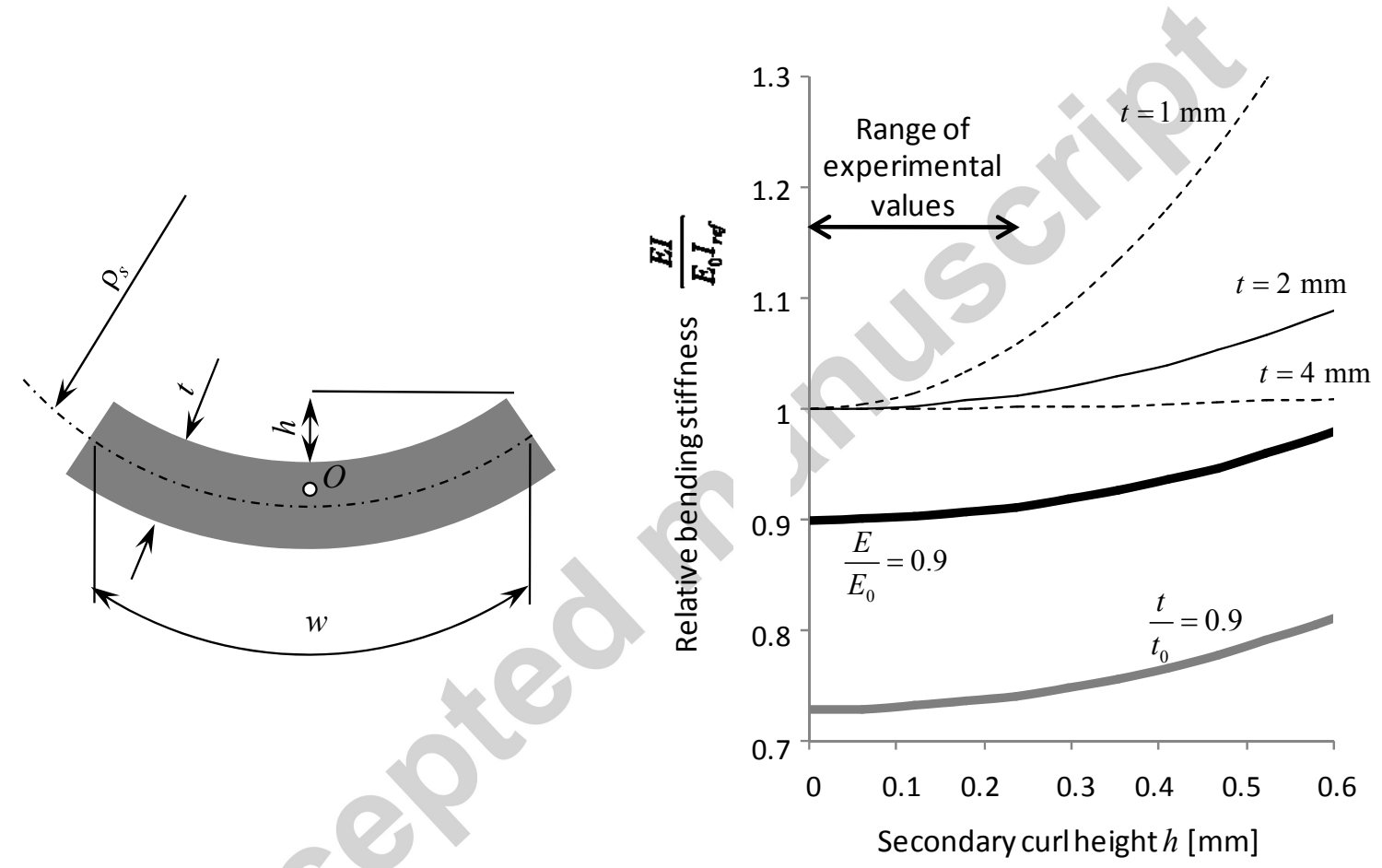

Figure 6. Influence of the secondary curvature on the bending stiffness of the BUT samples. The reference moment of inertia $I_{r e f}=w t_{0}^{3} / 12$. Point $O$ designates the centre of gravity of the cross-section.

4. 


\section{Numerical simulation of the BUT tests}

For the numerical simulation of forming processes including springback, static implicit FE codes are recommended. Here, Abaqus/standard was used to simulate the BUT experiments using the built-in elasto-plastic model. First, guidelines from the literature concerning the numerical simulation of stretch-bending tests were verified for the proposed geometries (thickness and width). Next, two classical hardening models were compared over a variety of loading conditions to investigate the ability using BUT tests to reveal domains of validity and invalidity for particular constitutive models and/or corresponding sets of parameters.

The finite element simulation for the BUT test was performed in the following four steps: bending, tensile pre-straining up to the required back force, drawing and springback. The tool was considered rigid, which is an acceptable assumption in this test configuration [17]. Due to the particular geometries investigated, solid elements were used to model the samples. A refined mesh was chosen for the entire zone that was subjected to bending. Due to symmetry, only the half-width of the specimen was meshed using ten elements. Figure 7 illustrates the main steps of the simulation and the typical FE mesh used for the simulations.

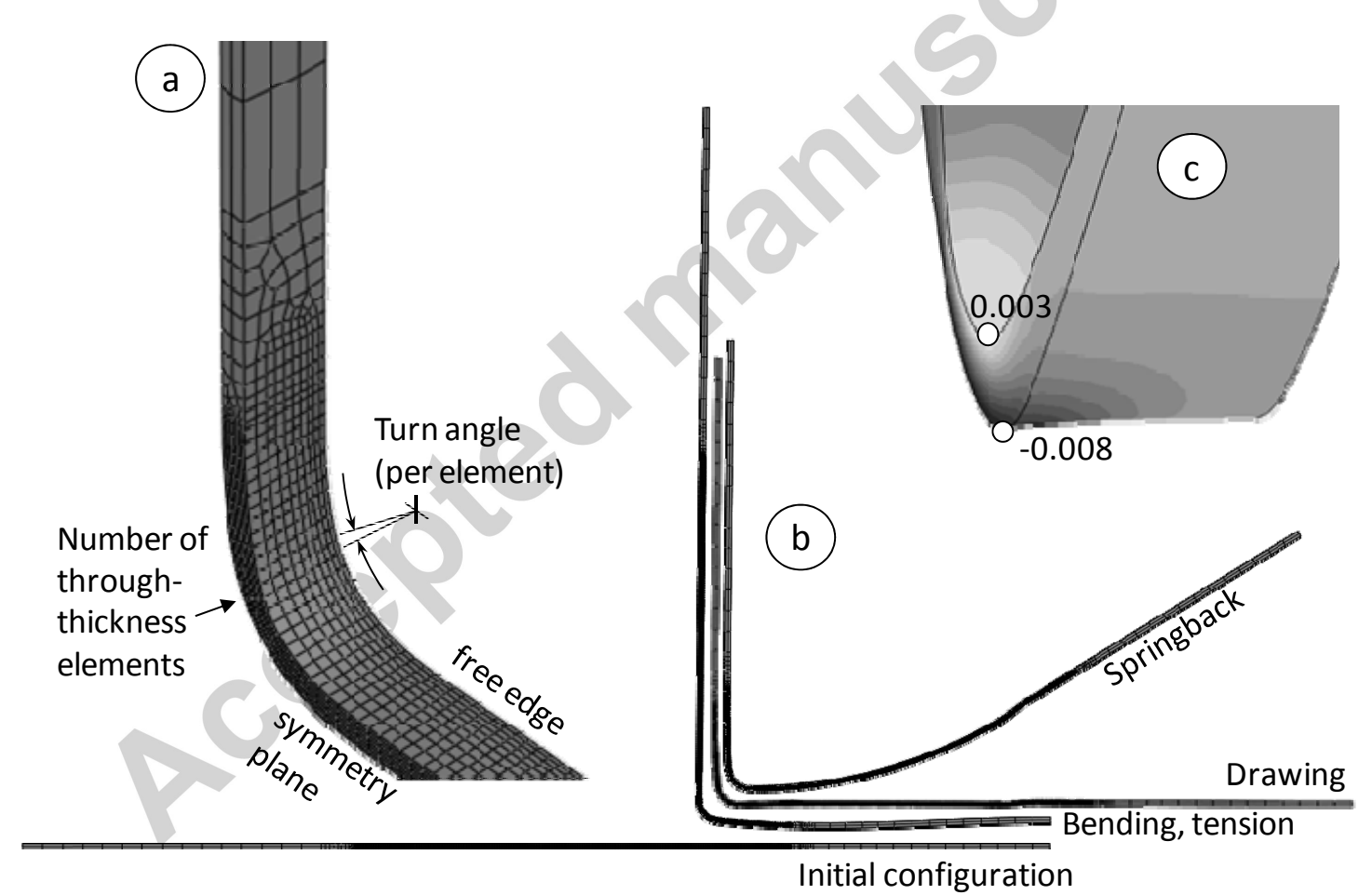

Figure 7. FE models of the experimental tests: (a) Mesh of the sample; (b) Main steps of the simulation; (c) Detail of the BUT deformation and 3D effects: secondary curvature and strain distribution (in the width direction) at the free edge for a 2-mm thick sample.

As emphasized in the literature, FE simulations of the BUT test are particularly demanding and costly. Very restrictive recommendations, especially with regard to mesh refinement, are reported. The particular geometries tested in this report have rarely been studied in the literature; thus, the sensitivity of the results to numerical parameters was investigated. The 
results of this sensitivity analysis are briefly summarized here for the 2-mm thick TRIP B sheet, with a tool radius of $5 \mathrm{~mm}$ and a back force factor of 0.5 , and using isotropic hardening. As already reported in the literature for thinner materials [7], the simulation of initial bending had virtually no influence on the final geometry after elastic unloading, although it induces non-negligible plastic strains: the springback angles predicted with and without the simulation of initial bending were identical. Figure 8 shows the impact of the number of elements through the thickness of the sheet when linear reduced-integration hexahedral elements are used. If only one such element is used through the thickness, bending cannot be simulated and the sample becomes straight again (with a springback angle of $-90^{\circ}$ ) after elastic unloading. The predicted angle depends on the number of elements in an oscillatory manner, which depends on the relative position of the elastic-plastic transition points with respect to the integration points $[8,18]$. Nevertheless, satisfactory convergence was quickly reached since the values obtained with four elements or more were within $\mathrm{a} \pm 1^{\circ}$ range, which is a typical error margin for the springback angle measurement. Eight elements were considered in the thickness direction for all of the simulations reported in this section. The number of elements in the length direction exhibited little influence, as observed in Table 3. The predicted values are very close to each other, and no trend was observed. Consequently, the selected meshes correspond to a $4^{\circ}$ turn angle per element, which lead to element aspect ratios close to one.

The element type had an important impact on the springback results - as expected when forming problems involve bending. Shell elements provided accurate results for thicknesses of $2 \mathrm{~mm}$ or less, but these elements proved insufficient for small $R / t$ ratios [7] and for 4-mm thick samples; thus, solid elements were preferred throughout. Table 4 shows that eight through-thickness elements are not sufficient to achieve convergence with each element formulation; fully integrated linear hexahedra predictions did not reach the reference values even when 14 elements were used (even though this corresponds to twice as many integration points in the thickness direction). This result is consistent with the recommendations of more than 50 through-thickness integration points given in [7], which seem to be required for particular types of elements. Plane stress two-dimensional predictions proved accurate due to the reduced width of the samples. Accurate predictions with plane strain elements were obtained only in particular cases, while significant errors occurred in some situations. Plane strain simulations were only valid for large $R / t$ ratios and should be avoided in the general case, especially with the sample geometry (width) under consideration. The predictions obtained with the reduced integration linear hexahedron were very close to those obtained with the quadratic hexahedron (used as reference), and this element was selected for subsequent simulations. 


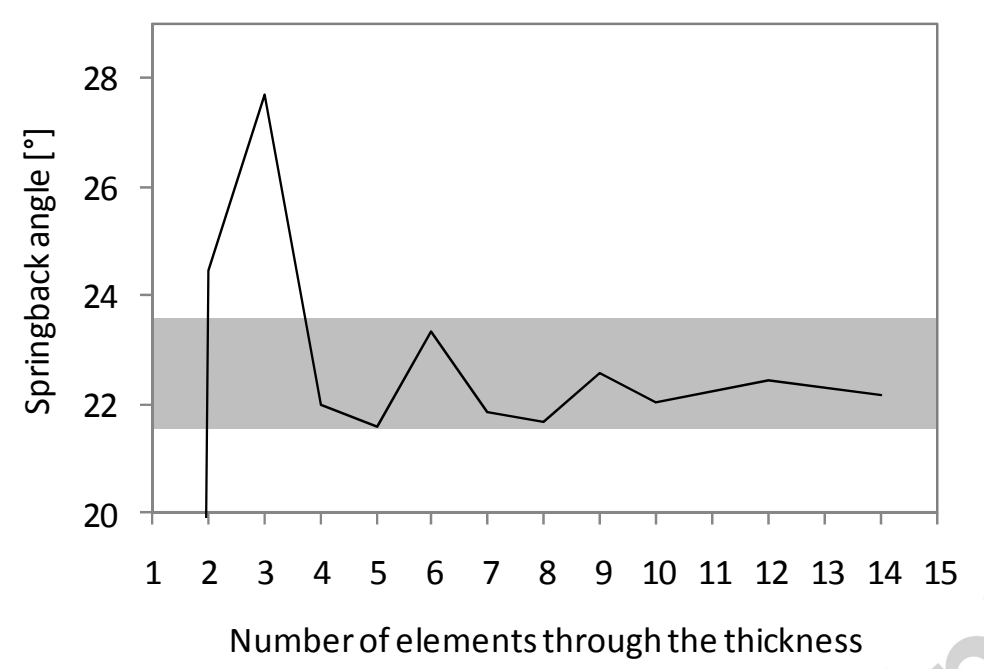

Figure 8. Sensitivity of the final geometry to the number of through-thickness elements (mesh refinement in thickness direction). The simulations correspond to a tool radius of $5 \mathrm{~mm}$ and a back force factor of 0.5 , using isotropic hardening.

Table 3. Sensitivity of the final geometry to mesh refinement in the length direction, characterized by the turn angle per element in the bending-unbending region (see Figure 7).

\begin{tabular}{lcccccccccc}
\hline Turn angle $\left[{ }^{\circ}\right]$ & 1 & 2 & 3 & 4 & 5 & 6 & 7 & 8 & 9 & 10 \\
\hline Springback angle $\left[^{\circ}\right]$ & 21.92 & 21.66 & 21.45 & 21.61 & 21.6 & 21.65 & 21.61 & 21.55 & 21.45 & 21.55 \\
\hline
\end{tabular}

Table 4. Sensitivity of the final geometry to the type of finite element.

\begin{tabular}{cccccc}
\hline & & \multicolumn{2}{c}{$R=5 \mathrm{~mm}$} & \multicolumn{2}{c}{$R=15 \mathrm{~mm}$} \\
\cline { 3 - 5 } & Element & \multicolumn{2}{c}{ Number } & of & through-thickness elements \\
& & 8 & 14 & 8 & 14 \\
\hline 3D hexahedra & Quadratic (C3D20) - reference & 22 & 22 & 36 & 36 \\
(linear, except & Reduced integration (C3D8R) & 22 & 22 & 36 & 36 \\
for C3D20) & Full integration (C3D8) & 25 & 24 & 39 & 39 \\
& Hybrid displ-pressure (C3D8H) & 25 & 24 & 39 & 39 \\
\hline \multirow{2}{*}{ 2D quadrangles } & Plane stress (CPS4I) & 40 & 40 & 36 & 36 \\
& Plane strain (CPE4I) & 46 & 46 & 42 & 42 \\
\hline
\end{tabular}


Associated elasto-plasticity material models are considered for the numerical simulation of the BUT tests. Such models are classically defined by the yield function (1) and the saturating, isotropic-kinematic hardening equations (2):

$$
\begin{gathered}
\bar{\sigma}\left(\boldsymbol{\sigma}^{\prime}-\mathbf{X}\right)-R-Y_{0} \leq 0 \\
\dot{R}=C^{R}\left(R^{s a t}-R\right) \dot{\bar{\varepsilon}} \text { and } \dot{\boldsymbol{X}}=C^{X}\left(X^{\text {sat }} \frac{\boldsymbol{\sigma}^{\prime}-\boldsymbol{X}}{\bar{\sigma}}-\boldsymbol{X}\right) \dot{\bar{\varepsilon}},
\end{gathered}
$$

where $\sigma$ is the Cauchy stress tensor, $\sigma^{\prime}$ is its deviator, $\bar{\sigma}$ designates the equivalent stress, $\boldsymbol{X}$ and $R$ are internal variables describing the current position and size of the yield surface, respectively, $\dot{\bar{\varepsilon}}$ is the equivalent plastic strain rate (plastic multiplier), and $Y_{0}$ defines the initial size of the yield surface. The material plastifies when the yield function vanishes. For the hardening model, the initial conditions $R(0)=0$ and $X(0)=0$ were used, and $Y_{0}, C^{R}, R^{s a t}, C^{X}$, and $X^{\text {sat }}$ are material constants. The von Mises yield function was used because the four AHSS are nearly isotropic. Accurate springback predictions based on the von Mises yield surface are available in the literature for various materials [7], and this model has the advantage of being coupled with combined hardening equations in Abaqus. Two variants of the hardening equations were used to emphasize the impact of the hardening model on springback predictions. The first variant incorporated the complete, combined isotropickinematic hardening described by equation set (2), while the second variant included only the isotropic hardening component $(\boldsymbol{X}(t)=\mathbf{0}, \forall t)$. The parameters of the two models have been identified previously by Brunet and co-workers [19] using bending-unbending tests to activate kinematic hardening. Details on the parameter identification procedure can be found in [20, 21]. This identification approach seems well suited for BUT simulations because the test loading conditions are very similar to the identification loading conditions. Figure 9 shows the response of the isotropic hardening and combined hardening models for the DP sheet steel (2$\mathrm{mm}$ thick). The Baushinger effect characteristic of DP steels can be observed even at small strains and was captured with the combined hardening model. The isotropic hardening model cannot describe the Baushinger effect; its parameters were identified in order to match those of the combined hardening model very closely along monotonic loading. This property is important when comparing the two model predictions against each other. 


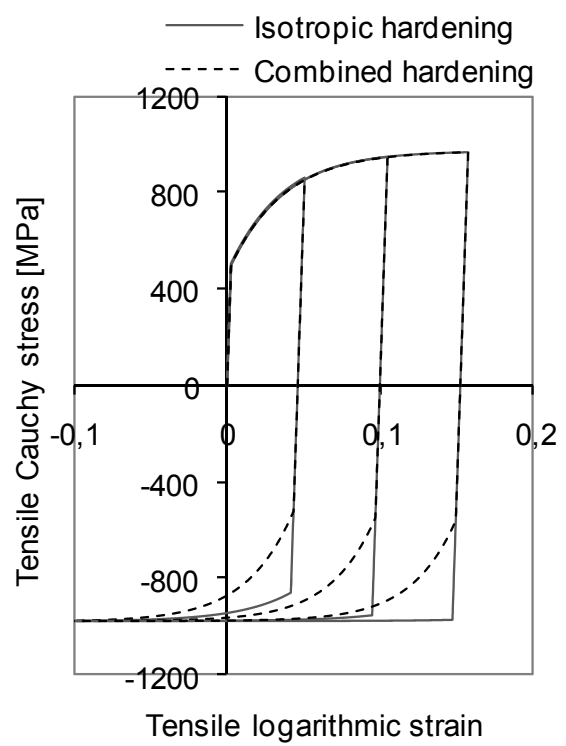

Figure 9. Tension-compression simulations with the isotropic hardening model (solid line) and the combined isotropic-kinematic hardening model (dashed line) for the DP steel.

The influence of the hardening model on springback angles for the 2-mm thick DP steel under various loading conditions is illustrated in Figure 10. The predictions made by the combined isotropic-kinematic hardening model were always closer to the experimental results than those made by the isotropic hardening model alone. However, the differences between the two models became very small when the tool radius-versus-thickness ratios were greater than five, or when the back force factors approached unity. This may partially explain why the isotropic hardening is so frequently successful in industrial applications including springback predictions. It is noteworthy that the best predictions were obtained with a tool radius of 10 $\mathrm{mm}$, corresponding to $R / t=5$ in this case. This result is likely due to a very appropriate identification procedure, because the $10-\mathrm{mm}$ tool radius is remarkably close to the $11-\mathrm{mm}$ bending radius used during the parameter identification experiments [19-21]. Here, the various sheet tension and tool radius conditions induced very different strain ranges and histories. Figure 11 illustrates the stress-strain evolutions in the DP steel samples for the nine different loading conditions. All the simulations led to reverse loading, and very different levels of pre-strain and total strain are attained. Consequently, different final strain distributions are induced through the thickness of the sheet, as shown in Figure 12. The strain component in the longitudinal direction is uniform, while the equivalent strain is at a maximum close to the surfaces. The strain level increases when the sheet tension increases and when the $R / t$ ratio decreases. 


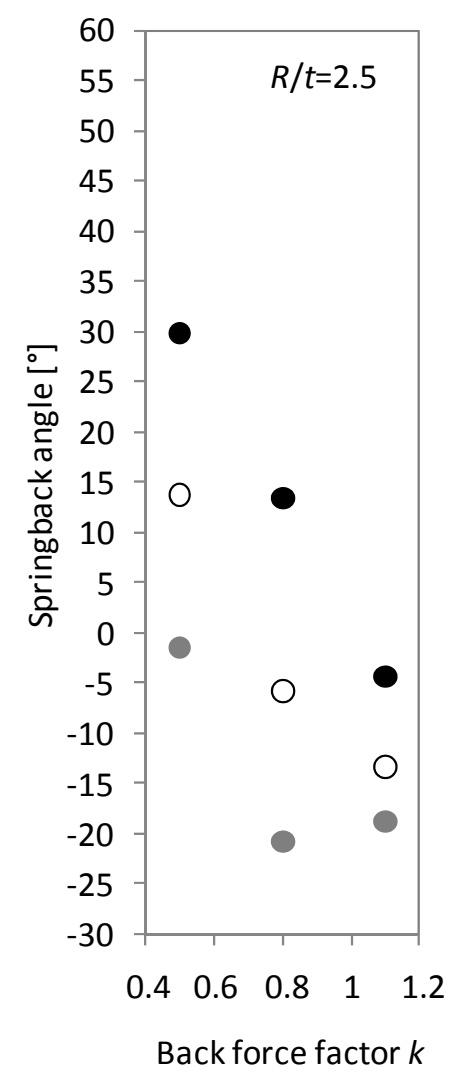

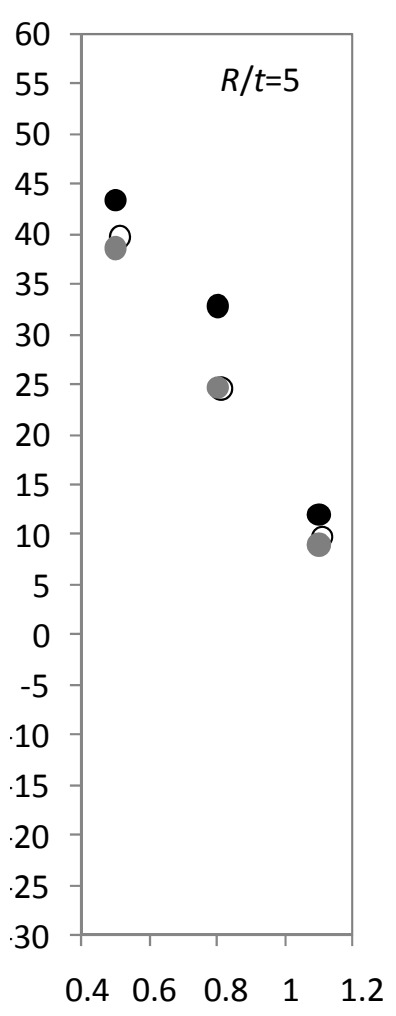

Back force factor $k$

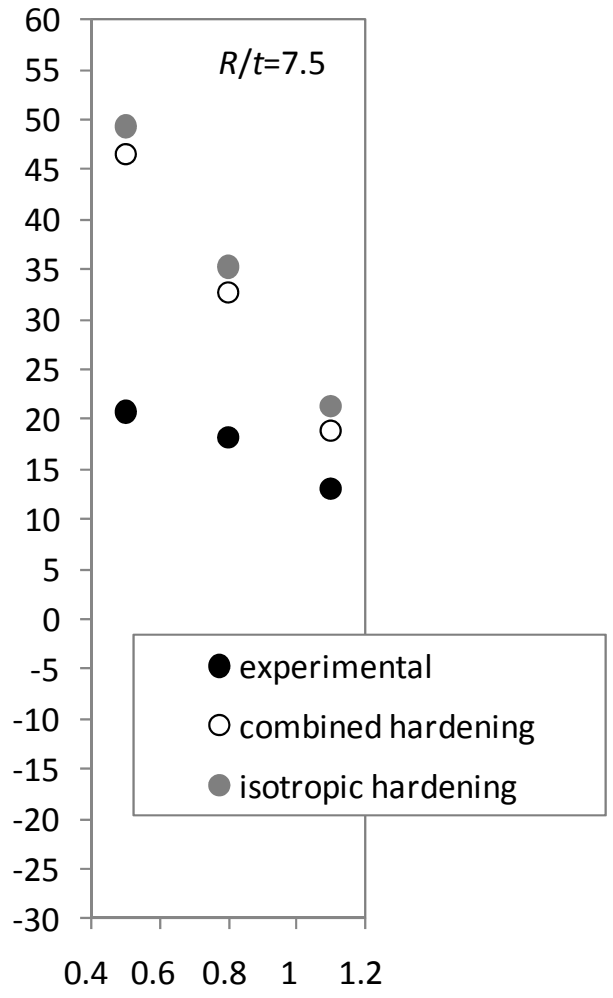

Back force factor $k$

Figure 10. Springback predictions with isotropic hardening and combined isotropic-kinematic hardening for the DP steel.

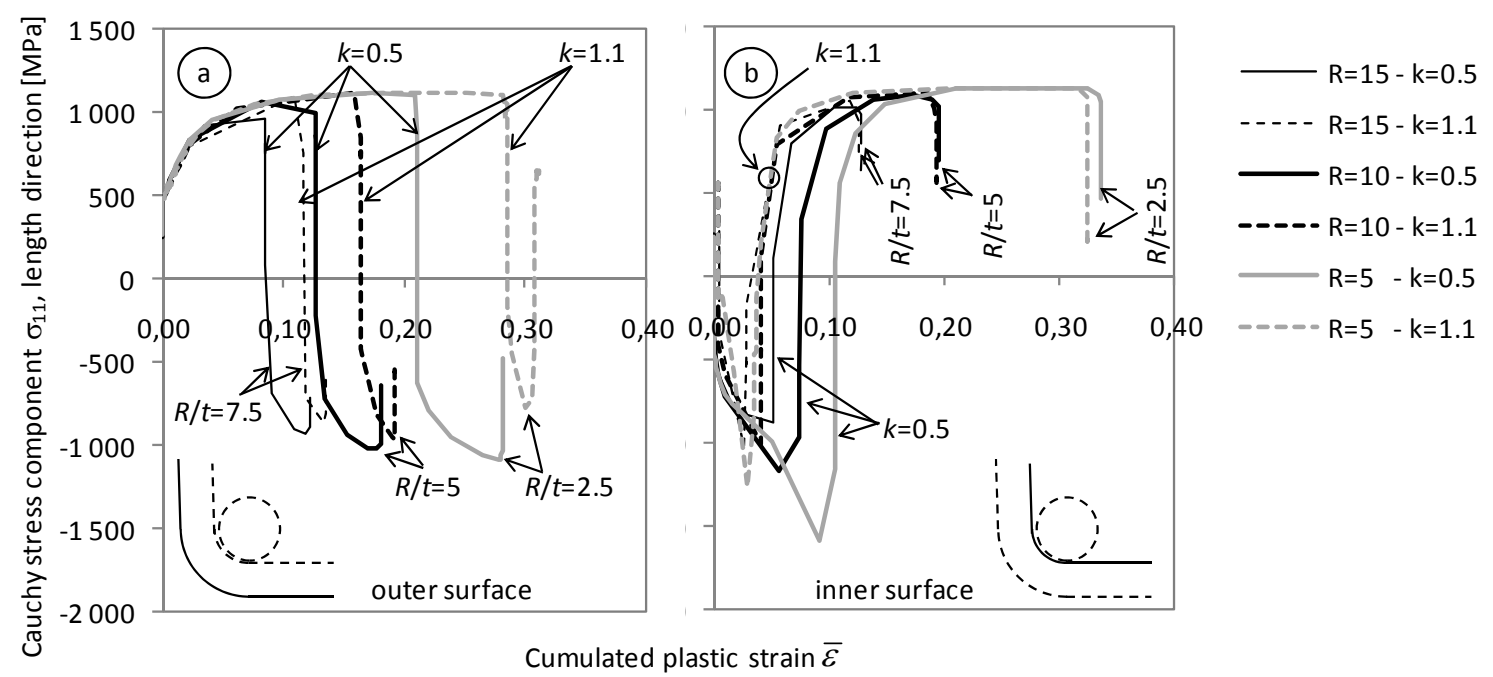

Figure 11. Evolution of the Cauchy stress component in the length direction of the sample during the BUT simulations for DP steel at material points situated on the outer surface of the sample (left) and on its inner surface (right). The combined hardening model is used with tool radii of $15 \mathrm{~mm}$ (thin lines), $10 \mathrm{~mm}$ (thick lines) and $5 \mathrm{~mm}$ (gray lines), using back force factors of 0.5 (solid lines) and 1.1 (dashed lines). 

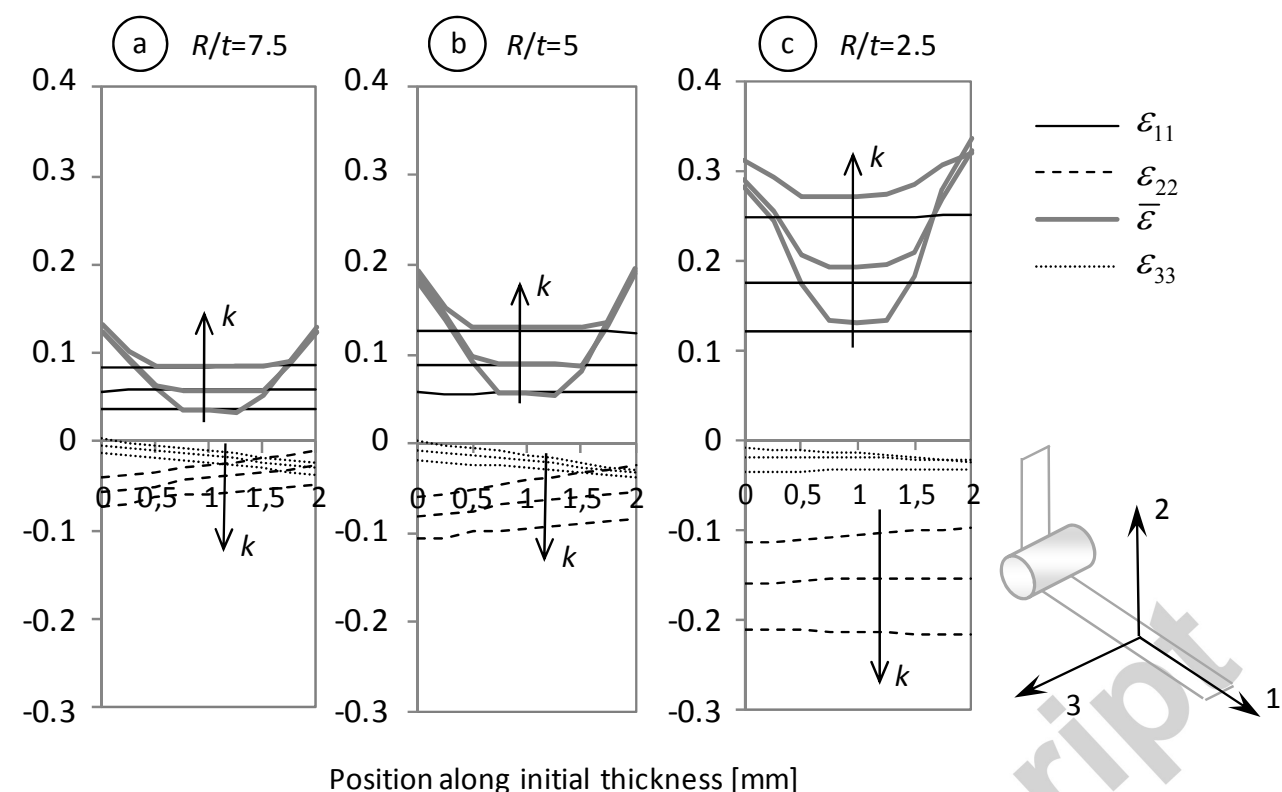

Figure 12. Through-thickness strain distributions for a tool radius of: a) $15 \mathrm{~mm}$, b) $10 \mathrm{~mm}$, and c) $5 \mathrm{~mm}$, and for three values of the sheet tension factor $k: 0.5,0.8$ and 1.1 . The effect of increasing sheet tension is indicated by the arrows. Directions 1, 2 and 3 designate the length, thickness and width directions, respectively.

Both models eventually underestimated springback with very small tool radii and overestimated springback with large tool radii. This result is consistent with the comparison between simulated and experimental tensile stress-strain curves shown in Figure 13. For $R=$ $15 \mathrm{~mm}(R / t=7.5)$, the tensile stress is slightly overestimated. For $R=5 \mathrm{~mm}(R / t=2.5)$, strains larger than 0.3 are reached, which are not covered by the experiment. One may, however, suppose that the stress is underestimated at strains larger than 0.15 . Springback naturally follows the same trends.

Together, these results suggest that even the combined kinematic hardening model adopted in the simulations is unable to predict all of the combinations of loading conditions in the series. This corroborates well with previous results obtained using channel drawing simulations [22], where very small tool radii were shown to increase the sensitivity of springback to different combined hardening models. The studies of $[19,20]$ have shown that the use of an enhanced kinematic hardening model involving two backstress tensors is able to correctly describe the small-strain transient response in bending-unbending loading. Thus, it would improve the predictions at large tool radii. While such models are also likely to correctly predict largestrain behavior [23], large strain parameter identification methods must be used [23-25]. It is noteworthy that using reduced sets of test conditions (e.g., only one tool radius) for the springback investigation would lead to inconsistent conclusions pertaining to the accuracy of the hardening model. On the contrary, using a wide range of test parameters allowed for a complete and discriminant analysis, within a single test facility. 


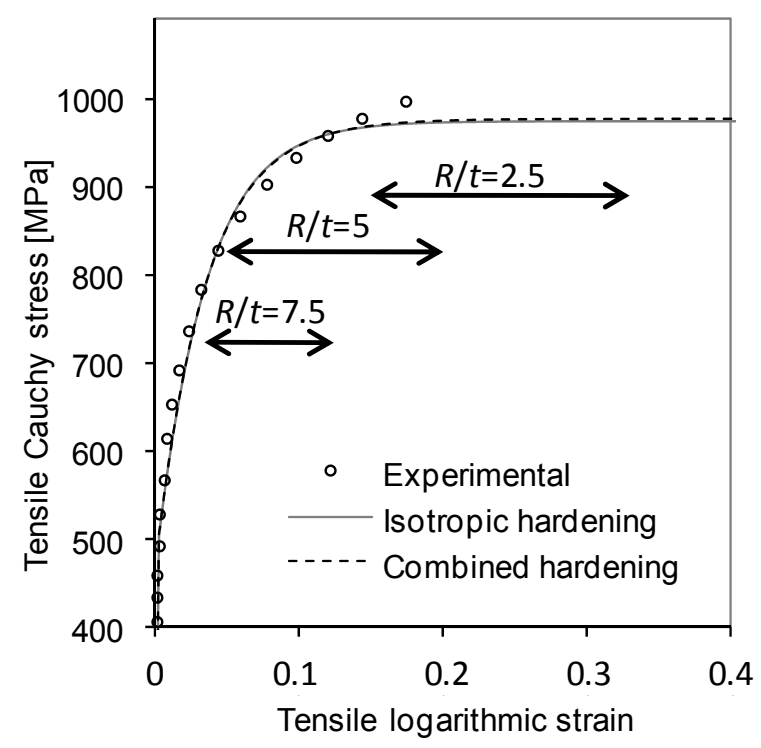

Figure 13. Tensile stress-strain curves predicted by the two models; the ranges of cumulated plastic strain are indicated for the three sets of simulations corresponding to the three tool radii.

Figure 12 also reveals that, due to the specific loading mode, the strain component in the thickness direction is significantly larger than the one in the width direction (despite the use of an isotropic yield surface in the simulations). Consequently, the sample width remains almost constant during the process, while its thickness is reduced significantly. As shown in Figure $14 \mathrm{a}$, the final sample thickness is consistently predicted in all cases, with an onverestimation of 0.01-0.05 $\mathrm{mm}$. Thickness is important for springback due to its influence on the bending stiffness (Figure 14b). The observed uniform thickness error is most certainly related to the plastic anisotropy of the material, which is neglected in the simulations. This approximation resulted in overall thicker, thus stiffer, samples. Finally, the good results for the tool radius of $10 \mathrm{~mm}$ are not only due to accurate stress predictions in the corresponding strain ranges but also due to the compensation of neglected factors such as plastic anisotropy (reducing springback by overestimating thickness, in this particular case), and the decrease of the apparent elasticity modulus (increasing springback [26-29]), etc. Table 5 shows that the thickness was overestimated at a larger extent with 2D elements, especially plane stress. Indeed, the plane stress condition is not entirely respected even for 12-mm wide specimens. Figure 15 shows the evolution of all of the diagonal stress components at material points located on the inner/outer surfaces of the sample. The stress component in the width direction $\left(\sigma_{33}\right)$ is far from zero and complex stress states are particularly observed during the compressive stages. This explains the stress "overshoot" that is clearly visible in Figure 11 (with respect to Figure 9 and Figure 13), which may influence the final stress distribution and eventually springback. Consequently, 3D solid elements are required to simulate processes involving bending over small radii. 

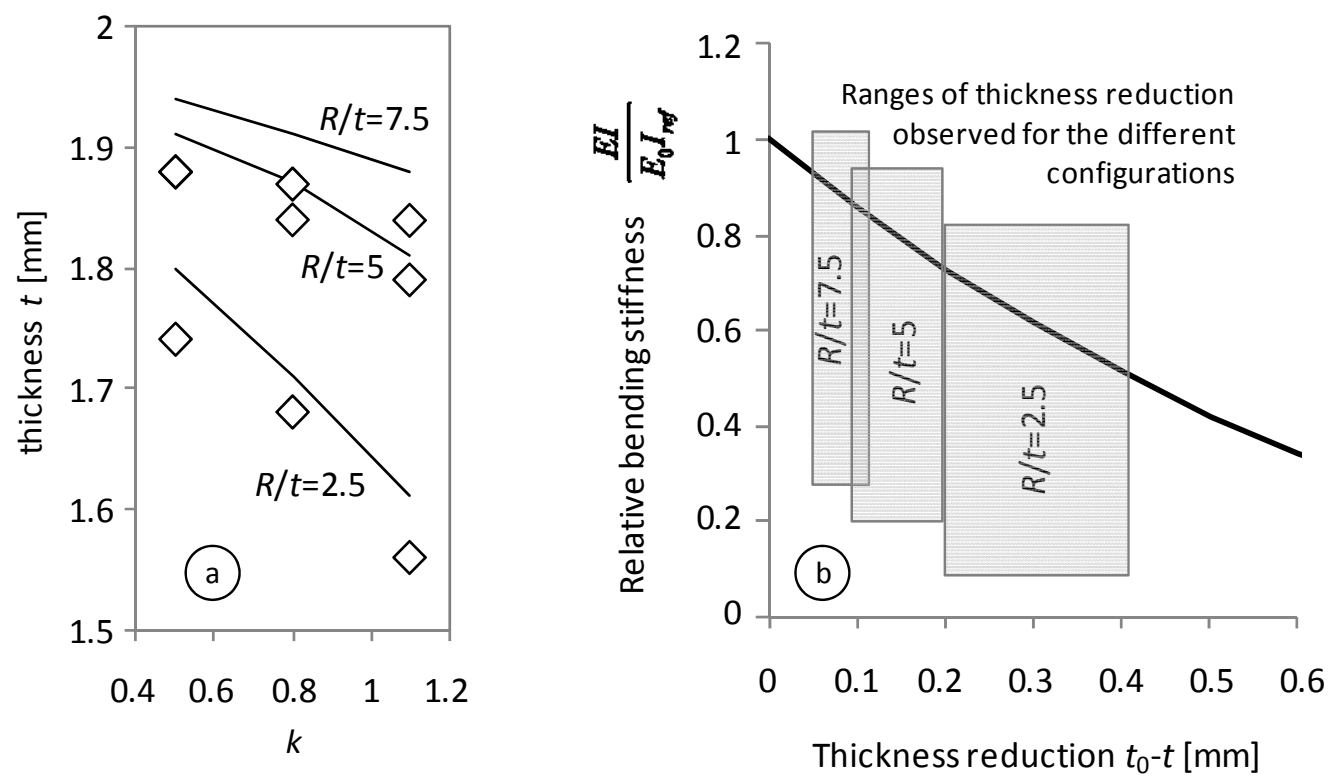

Figure 14. a) Thickness predictions (solid lines) and measurements (symbols) for the DP steel in the nine test configurations. b) Theoretical variation of the relative bending stiffness as a function of thickness reduction.

Table 5. Final sample thicknesses predicted with different finite elements for the 2-mm DP steel, using combined isotropic-kinematic hardening model.

\begin{tabular}{cccc}
\hline \multirow{2}{*}{ Tool radius $[\mathrm{mm}]$} & \multicolumn{3}{c}{ Thickness $[\mathrm{mm}]$} \\
\cline { 2 - 4 } & 3D element & Plane strain el. & Plane stress el. \\
\hline 15 & 1.94 & 1.94 & 1.96 \\
5 & 1.8 & 1.79 & 1.88 \\
\hline
\end{tabular}

\section{Conclusions}

In this work, thick sheet AHSS materials were investigated using BUT tests with 12-mm wide specimens and finite element simulations to address the relevance and validity of guidelines from the literature concerning springback. The following conclusions were drawn:

- Springback decreased almost linearly as sheet tension increased. In general, springback decreased for larger tool radii, this effect being less significant than that of sheet tension. However, this trend was completely reversed at small $R / t$ ratios. Below a certain limit, smaller tool radii induced a decrease in springback until annulation or even springforward. For the materials, thicknesses and back forces examined in this work, the limit between these two zones was approximately $R / t=5$. 
- Secondary curvature had little influence on the results because the Searle parameter was less than unity in all cases due to the chosen sample geometry. Consequently, no interference from changes in cross-section shape was observed when studying the effects of other parameters.

- Thickness reduction systematically accompanied the BUT tests and was of primary importance on springback. This is believed to restrict the application of analytical solutions, finite element plane strain or plane stress solutions, or even shell element solutions for small $R / t$ and $w / t$ values.

- The curvature appeared to be the most intuitive measure for side-wall springback.

- The mesh density requirements for finite element springback predictions were more demanding than for forming simulations, as frequently underlined in the literature; eight elements were required in the through-thickness direction. Plane strain and plane stress 2D models could not accurately predict all of the loading conditions investigated.

- Using the kinematic hardening model improved the predictions made with the isotropic hardening model alone. However, both models predicted similar springback results for back forces close to unity or for large $R / t$ ratios. The BUT tests proved useful for addressing the accuracy of the hardening model, provided that several testing conditions (sheet tension and $R / t$ ratio being the main factors) were combined.

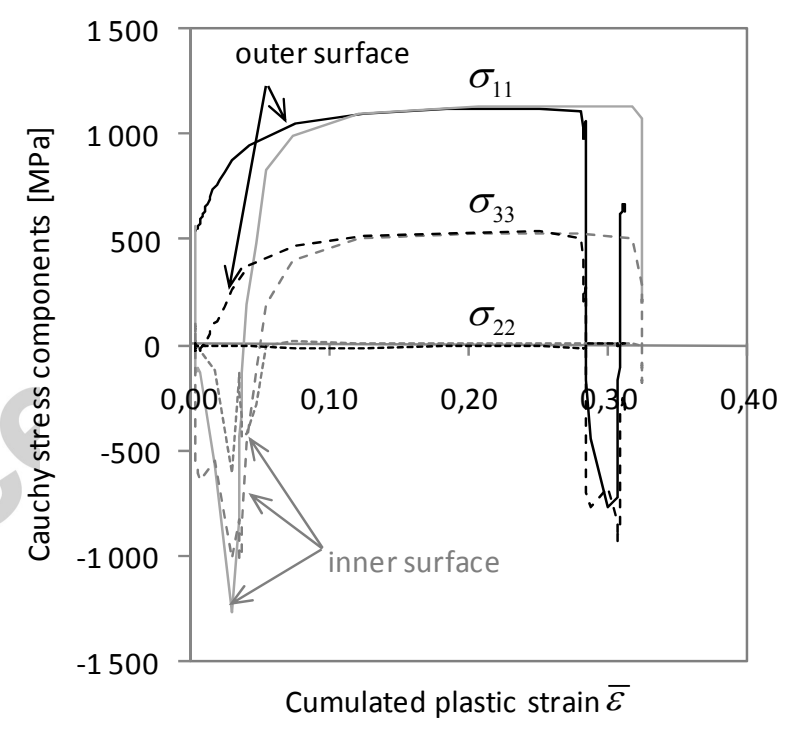

Figure 15. Evolution of the diagonal Cauchy stress components in the sample frame for DP steel with a tool radius $R=5 \mathrm{~mm}$ and sheet tension factor $k=1.1$ for material points located on the outer (black lines) and the inner surface of the sample (gray lines) in its plane of symmetry. The combined hardening model is used. 


\section{Acknowledgements}

The authors would like to thank X. Lemoine (ArcelorMittal Maizière R\&D Automotive Products) for providing the materials and experimental data, M. Brunet (LaMCoS, INSA Lyon) for providing the material parameters, and S. Khan, T. Cwiekala, A. Nachit, O. Bomont and his team for their help with simulations, experiments or device fabrication, respectively. This work has been financially supported by the Agence Nationale de la Recherche, France, through the RNMP project "FORMEF".

\section{References}

[1] A. E. Makinouchi, E. Nakamachi, E. Onate, R. H. Wagoner, eds, NUMISHEET '93, The Institute of Physical and Chemical Research, 1993.

[2] M. Sulonen, P. Eskola, J. Kumpulainen, A. Ranta-Eskola, A reliable method for measuring the friction coefficient in sheet metal forming, IDDRG Working Group Meeting, Paper WG III/4, Tokyo, 1981.

[3] G. J. Wenzloff, T. A. Hylton, D. K. Matlock, Journal of Materials Engineering and Performance 1 (1992) 609-614.

[4] T. Kuwabara, S. Takahashi, K. Akiyama, Y. Miyashita, SAE Technical paper 950691 (1995) 1-10.

[5] T. Kuwabara, S. Takahashi, K. Ito, Springback analysis of sheet metal subjected to bending-unbending under tension Part II (experimental verification), in Advanced Technology of Plasticity, Proc. 5th ICTP, vol. II, Columbus, Ohio, p. 747-750, 1996.

[6] W. D. Carden, L. M. Geng, D. K. Matlock, R. H. Wagoner, International Journal of Mechanical Sciences 44 (2002) 79-101.

[7] K. P. Li, W. P. Carden, R. H. Wagoner, International Journal of Mechanical Sciences 44 (2002) 103-122.

[8] R. H. Wagoner, M. Li, International Journal of Plasticity 23 (2007) 345-360.

[9] J. F. Wang, R. H. Wagoner, D. K. Matlock, F. Barlat, International Journal of Solids and Structures 42 (2005) 1287-1307.

[10] T. B. Hilditch, J. G. Speer, D. K. Matlock, Journal of Materials Processing Technology 182 (2007) 84-94.

[11] S. G. Racz, S. Khan, H. Chalal, F. Abed-Meraim, T. Balan, Prediction of springback after draw-bending test using different material models, in Advances in Materials Processing Technology, Paris, p. 419-424, 2010.

[12] Z. C. Xia, D. Zeng, SAE Technical paper 2006-01-0147, SAE, Warrendale, PA, 15096 (2006)

[13] X. Lemoine, Steels and experiments, Formef project report, ArcelorMittal R\&D, Maizières-lès-Metz, 2006.

[14] M. Kleiner, M. Schikorra, R. Govindarajan, A. Brosius, Springback analysis of sheet metals regarding material hardening, in 11th Int. Conf. on Sheet Metal, p. 712-728, 2005.

[15] A. W. Hudgins, D. K. Matlock, J. G. Speer, C. J. Van Tyne, Journal of Materials Processing Technology 210 (2010) 741-750.

[16] G. Searle, Experimental Elasticity: A Manual for the Laboratory, Cambridge University Press, Cambridge, 1908.

[17] I. N. Vladimirov, M. P. Pietryga, S. Reese, Journal of Materials Processing Technology 209 (2009) 4062-4075.

[18] I. A. Burchitz, T. Meinders, International Journal for Numerical Methods in Engeneering 75 (2008) 533-554. 
[19] F. Sabourin, M. Brunet, Identification of hardening models, LaMCoS, INSA Lyon, Technical report, 2007.

[20] J. Carbonnière, S. Thuillier, F. Sabourin, M. Brunet, P. Y. Manach, International Journal of Mechanical Sciences 51 (2009) 122-130.

[21] M. Brunet, F. Morestin, S. Godereaux, Journal of Engineering Materials and Technology 123 (2001) 378-383.

[22] B. Haddag, T. Balan, F. Abed-Meraim, International Journal of Plasticity 23 (2007) 951-979.

[23] H. Haddadi, S. Bouvier, M. Banu, C. Maier, C. Teodosiu, International Journal of Plasticity 22 (2006) 2226-2271.

[24] A. E. Tekkaya, Steel Research 65 (1994) 65-70.

[25] A. E. Tekkaya, K. Pöhlandt, K. Lange, CIRP Annals - Manufacturing Technology 31 (1982) 171-174.

[26] F. Morestin, M. Boivin, Nuclear Engineering and Design 162 (1996) 107-116.

[27] J. C. Gelin, S. Thibaud, N. Boudeau, Modelling and simulation of the influence of forming processes on the structural behavior of high strength steels, in Proceedings of Numisheet 2005, Detroit, MI, USA, p. 101-106, 2005.

[28] R. M. Cleveland, A. K. Ghosh, International Journal of Plasticity 18 (2002) 769-785.

[29] H. Laurent, R. Grèze, P. Y. Manach, S. Thuillier, International Journal of Mechanical Sciences 51 (2009) 233-245. 
Title : Springback of thick sheet AHSS subject to bending under tension Authors : Hocine Chalal, Sever-Gabriel Racz, Tudor Balan

\section{Highlights}

- Thick sheet AHSS materials were experimentally and numerically investigated by means of bending-under-tension tests

- Tool-radius vs thickness ratio showed a strongly non-linear effect on springback

- Kinematical hardening consistently improved predictions but didn't prove needed at large sheet tensions or large $\mathrm{R} / \mathrm{t}$ ratios

- Secondary curvature had little influence while the sheet thinning was shown to have a primary influence on springback. 